\title{
Growth of ancient continents
}

The formation of chemically enriched continental crust and, correspondingly, the depleted mantle reservoir, represents an important stage of tectonic evolution and chemical differentiation on Earth. However, it remains challenging to accurately determine when chemical segregation of enriched and depleted components first occurred, and identify how these differentiated domains contribute to later stages of crustal formation.
Ann Bauer from the University of Wisconsin, WI, USA, and colleagues, coupled analysis of $\mathrm{U}-\mathrm{Pb}$ and $\mathrm{Lu}-\mathrm{Hf}$ isotopes in zircons from the Acasta Gneiss Complex (AGC), 2.9-4.0 Ga metamorphosed crust, to investigate chemical differentiation of the early Earth. Initial results indicated the presence of both enriched (negative $\varepsilon_{\mathrm{Hf}}$ ) and depleted (positive $\varepsilon_{\mathrm{Hf}}$ ) isotopic signatures in the AGC zircons. However, the positive $\varepsilon_{\mathrm{Hf}}$ values measured in some zircons can be assigned to the presence of late

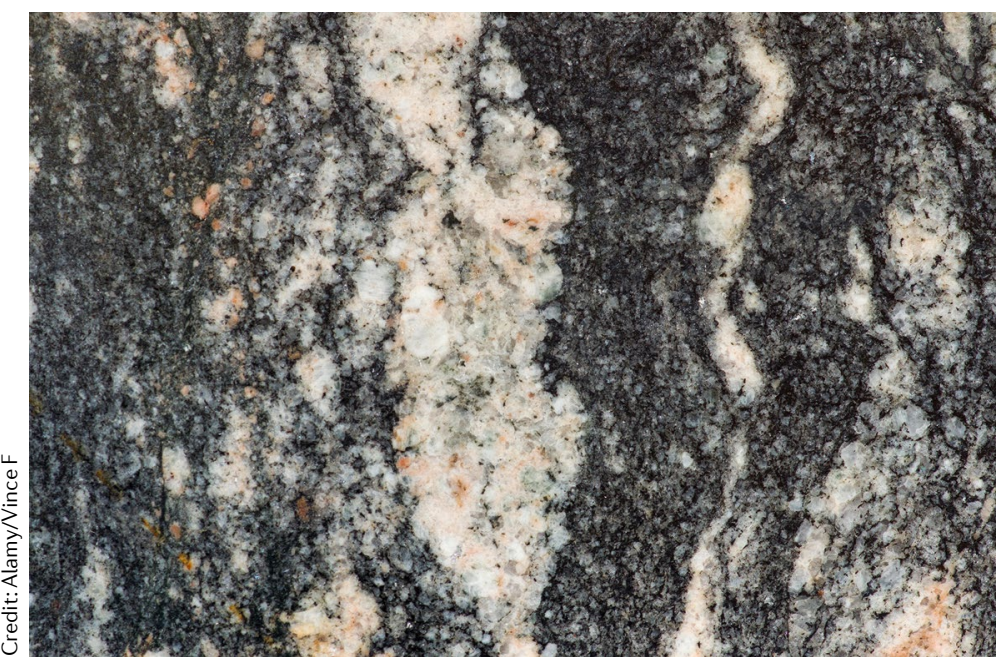

radiogenic overprints. Therefore, the isotopic composition of the zircons indicate that the $>3.6 \mathrm{Ga}$ rocks of the AGC formed through melting and reworking of an enriched reservoir (negative $\varepsilon_{\mathrm{Hf}}$ ), which must have separated from the mantle prior to $4.2 \mathrm{Ga}$. In addition, the lack of evidence for positive $\varepsilon_{\mathrm{Hf}}$ values in the primary AGC zircons indicates that a depleted mantle reservoir did not contribute to the formation of the AGC and, potentially, did not develop until the Paleoarchean.

Although there is no evidence in the zircon record of the AGC for the widespread development of a depleted mantle reservoir in the Hadean, ancient zircons (>3.5-4.0 Ga) from other terranes, as well as detrital records, should be targeted in the future to test this hypothesis. Nevertheless, the presence of enriched isotopic signatures in the AGC zircons indicates that segregation of an enriched proto-crust likely occurred within the first 500 Myr of Earth's history.

Matthew Gleeson ORIGINAL ARTICLE Bauer, A. et al. Unraveling the complexity of zircons from the 4.0-2.9 Ga Acasta Gneiss Complex. Geochim. Cosmochim. Acta https://doi.org/10.1016/j.gca.2020.05.023 (2020) 